\title{
Modelling of traffic safety of traditional mainline toll plazas
}

\author{
Muamer Abuzwidah ${ }^{1, *}$, Mohamed Abdel-Aty ${ }^{2}$ \\ ${ }^{1}$ Department of Civil and Environmental Engineering, University of Sharjah, Sharjah, UAE \\ ${ }^{2}$ Department of Civil, Environmental and Construction Engineering, University of Central Florida, \\ Orlando, Florida
}

\begin{abstract}
Freeways and expressways are considered an important part of any successful transportation system. These facilities carry the majority of daily trips on the transportation network. Although expressways (Toll Roads) offer high level of service, and are considered the safest among other types of roads, traditional toll plazas may have both safety and operational challenges. The traditional toll facilities still experience many crashes, many of which are severe. Therefore, the main focus of this paper is to evaluate the effect of tollbooths' number and types (i.e. cashier lanes, coin lanes and Electronic Toll Collections (ETC) lanes) on safety performance at traditional toll plazas. The literature showed that about 30 to 40 percent of the total crashes on expressways occur at these facilities. An extensive data collection was conducted that included 42 traditional mainline toll plazas located on approximately 750 miles of expressways in Florida, and multiple analytical techniques were used. Based on the finding in this paper, choosing locations for the toll plazas that have safe distances from the interchanges, installing flashing lights at night time, and finding ways to improve signage and road marking are potential means of reducing lane changes before tollbooths. More research is needed and researchers may build on the results of this study.
\end{abstract}

\section{Introduction}

The use of toll roads has risen dramatically in many countries around the world, and in some countries, toll roads' miles have almost doubled in the past decade. In the United States, there are currently many tolled road facilities; these facilities vary in type, size, ownership, and tolling systems deployed (Abuzwidah et al., 2014). Some of these facilities are private along with those owned and operated by various public agencies around the States (Abuzwidah, 2011) (Yang et al., 2014).

\footnotetext{
*Corresponding author: mabuzwidah@sharjah.ac.ae
} 
Even though toll roads offer high mobility benefits, traditional toll facilities may pose high traffic safety risk (Abuzwidah et al., 2014). The literature also showed that different toll collection systems have been adopted by different toll agencies around the world (Mohamed et al., 2000) (Schaufler, 1997). The most common toll collection systems can be summarized as follows:

1. Traditional Mainline Toll Plaza (TMTP); this design requires vehicles to rapidly decelerate, navigate through different fare transaction options, and then accelerate and merge with traffic (Miami-Dade Expressway, 2014) (McDonald, and Stammer, 2001). These confusing maneuvers constitute safety challenges and form high risk locations on toll roads.

2. Hybrid Mainline Toll Plaza (HMTP); this system retrofits existing tollbooths with express open Electronic Toll Collection (ETC) lanes. This design is allowing more than 81 percent of the vehicles in Florida to travel at full speeds using electronic transponders or license plate recognition technology in an open road environment with fewer diverge and merge maneuvers before and after the toll plaza. The HMTP design combines either express Open Road Tolling (ORT) lanes on the mainline and separate traditional toll collection to the side, or traditional toll collection on the mainline and separate ORT lanes to the side (FTE, 2014). However, the HMTP is widely deployed by many toll authorities such as in Florida, Illinois, New Jersey, and many other states.

3. All-Electronic Toll Gantry or All-Electronic Toll Collection (AETC); this system is completely barrier-free that replaces all tollbooths with regular express ETC lanes to change the toll plaza to be similar to regular segments. The AETC system allows driving straight through an open road without needing to change lanes, stop the vehicle, or even slow down to pay a toll. The payment will be done automatically, instantly and accurately by using the automatic toll collection transponder known as prepaid transponder (FTE, 2015).

Past studies and the current data have indicated that certain locations at the TMTP and HMTP are more likely to experience traffic crashes than the regular segments on the expressway. In April 2006 in Washington, D.C., investigators for the U.S. National Traffic Safety Board (NTSB) revealed that the most dangerous locations on the highways are toll plazas. In the same year, the NTSB reported that 49 percent of all crashes on expressways in Illinois occurred at toll plazas, and three times as many people died in them as in crashes on the rest of the same roadways. Also, 30 percent of all crashes on the Pennsylvania Turnpike happen at toll plazas and 38 percent of all collisions on New Jersey toll highways are toll plaza incidents (NTSB, 2014). An older study (Mohamed et al., 2000) found that about 32 percent of the total crashes that occurred on the Orlando expressway system were located at the traditional mainline toll plazas.

However, there are some obstacles to the use of the HMTP and AETC systems in many countries because these systems require good arrangements between the tolling agencies and the department of motor vehicles database. These arrangements are needed to identify and bill drivers who do not have the prepaid transponder. This processing is called Toll-ByPlate program, which is an image based electronic toll collection system that uses photographic images of the vehicle's license plate to identify the customers responsible for payments and bill them (FTE, 2015).

The use of the HMTP and AETC systems has demonstrated measured improvements in traffic operations and environmental issues. Also, it was proved that some simple and quick treatments could improve safety at TMTP (Sze et al., 2008). For example, (Wong et al., 
2006) evaluated the effects of a traffic guidance scheme for auto-toll lanes on traffic safety at TMTP and they found that the overall lane-changing rate decreased significantly by 23 percent and the pooled conflict count decreased sharply by 44 percent, also the crash count decreased sharply by 38 percent. However, there is a lack of research that compares and evaluates the safety impacts of using different toll plaza types. So, there is an urgent need to assess the traffic safety effects of these facilities.

To the best of our knowledge, there were no studies that evaluated the safety impacts of tollbooths number on the mainline toll plazas. Therefore, the main focus of this paper is to evaluate the effect of tollbooths number and types (i.e. cashier lanes, coin lanes and Electronic Toll Collections (ETC) lanes) on safety performance at traditional toll plazas; as well as providing safety guidelines for these facilities to promote safety on expressways.

\section{Methodology}

Negative Binomial Regression Model: Count data is usually modeled using a Poisson distribution; the main characteristic of the Poisson distribution is that its mean is equal to its variance. Several studies found that a negative binomial distribution fits crash frequency data better (Brown et al., 2006) (Abdel-Aty and Radwan, 2000). The Negative Binomial (NB) is similar to a Poisson distribution, though its variance is greater than its mean (Agresti, 2002). The NB model can be used to estimate crashes at locations, such as toll plaza segments (Chang, 2005).

$\mathrm{P}(\mathrm{yi}) \sim \operatorname{Negbin}(\lambda \mathrm{i}, \mathrm{k})$ :

$$
\frac{\Gamma\left(1 / \mathrm{k}+\mathrm{y}_{\mathrm{i}}\right)}{\mathrm{y}_{\mathrm{i}} ! \Gamma(1 / \mathrm{k})}\left(\frac{\mathrm{k} \lambda_{\mathrm{i}}}{1+\mathrm{k} \lambda_{\mathrm{i}}}\right)^{\mathrm{y}_{\mathrm{i}}}\left(\frac{1}{1+\mathrm{k} \lambda_{\mathrm{i}}}\right)^{1 / \mathrm{k}}
$$

Where, $\mathrm{y}=$ number of crashes on a certain location at a certain period,

$\lambda=$ Expected number of crashes on a certain location at a certain period

$\mathrm{k}=$ over-dispersion parameter.

The NB estimation equation is given as follows;

$$
\log \lambda_{i}=\log \left(E V_{i}\right)+\left(\beta_{0}+\beta X_{i}+\varepsilon_{i}\right)
$$

Where $\lambda_{i}$ is the estimated number of crashes at location $i ; \beta$ is a vector of explanatory variables, and $\mathrm{EV}_{i}$ is the exposure variable which is included in models as an offset term to account for unequal exposure to crashes along toll plazas. Count models such as NB need a mechanism to deal with different exposure scenarios. For example the Annual Average Daily Traffic (AADT), or expected number of crashes, can be included as an exposure offset term in NB models (Chen, 1997). By offsetting the exposure, the response variable becomes the $\log$ crash frequency at a certain location. $\varepsilon_{i}$ is the term adjusting for over dispersion. It is an error term due to a combination of variables omitted from the model and pure randomness. Maximum Likelihood Estimation (MLE) is used to estimate the coefficients of the explanatory variables and the over dispersion parameter. The goodness of fit of the NB model is measured by analyzing the over dispersion parameter. 


\section{Data description}

Different tolling systems are expanding on the Florida expressways in the past decade. Multiple sets of data maintained by Florida Department of Transportation (FDOT, 2015) were used in this study including:

Crash Analysis Reporting (CAR) system, Roadway Characteristics Inventory (RCI) system, TranStat IView aerial mapping system, and Financial Project Search Database. Moreover, Google Earth and the publication reports of Florida Turnpike and Central Florida Expressway Authority (CFX, 2015) were used to verify the toll plazas' characteristics. A 42 mainline toll plazas located on approximately 750 miles of toll roads in Florida were selected. Crash data from four-year period (2011-2014) were investigated. Crashes that occurred within the influence areas ( 1 mile before and 0.5 mile after the centerline of the mainline toll plaza) (MUTCD, 2015) were extracted from the crash database.

\section{Analysis and results}

\subsection{Part I : Effect of the total number of tollbooth on the safety at TMTP}

Data from 42 Traditional Mainline Toll Plazas (TMTP) were used in this approach. Crash data from a four-year period (2011, 2012, 2013 and 2014) was investigated. Figure 1 shows Traditional Mainline Toll Plazas. This design combines express lanes and traditional cash lanes.

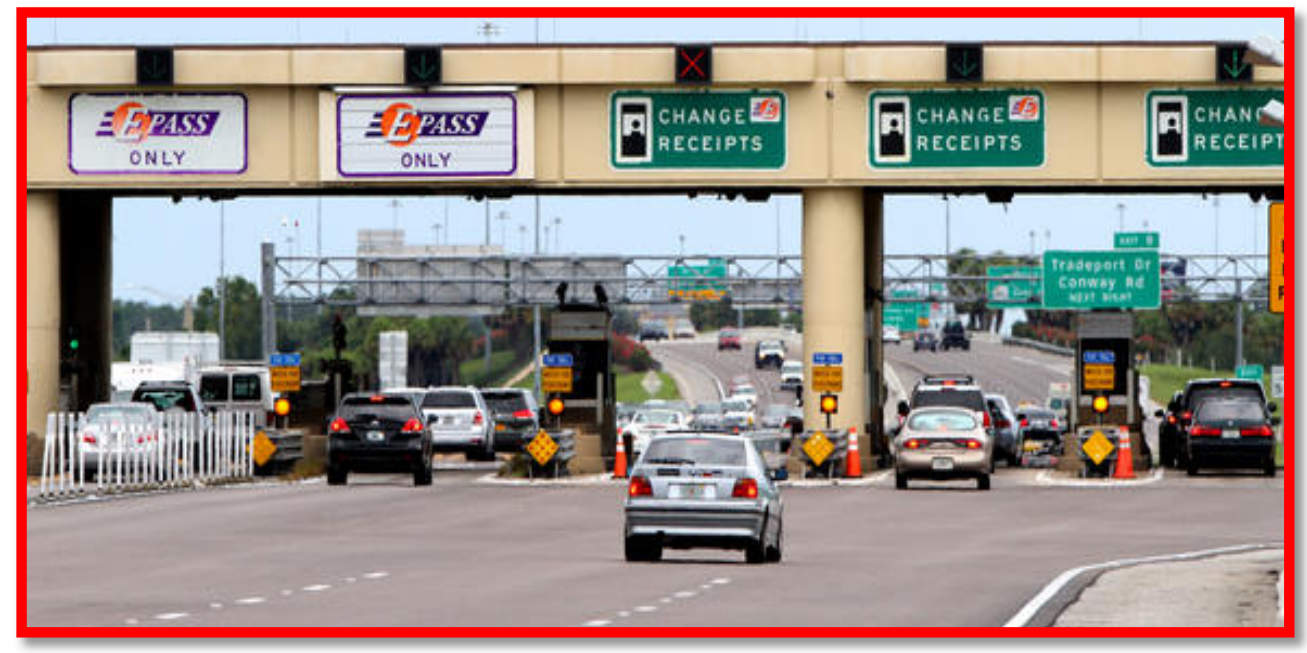

Fig. 1. Traditional Mainline Toll Plazas. (Source: (FTE, 2015))

A series of Negative Binomial (NB) models were fitted to establish the relationships between traffic and roadway characteristics, and crash frequency at the vicinity of TMTPs. Exploratory modeling indicated that the crash frequency is not significantly associated with Reversible Electronic Toll Collections (ETC) lanes, number of entry and exit ramps, and distance to entry and exit ramps.

Table 1 shows the parameter estimates of the final model. It should be noted that in some TMTPs, there are a Reversible ETC lanes based on the peak hours. Only log Annual Average Daily Traffic (AADT) and the number of tollbooths came out to be significant with the expected signs. The coefficient of both variables have a positive sign, which indicates that as they increase, the frequency of TMTP-related crashes increases. 
Table 1. Estimates of coefficients for Effect of the number of tollbooths on the safety.

\begin{tabular}{|c|c|c|c|c|c|}
\hline \multicolumn{5}{|c|}{ Negative Binomial } \\
\hline \multicolumn{4}{|c|}{ Negative Binomial: Analysis Of Maximum Likelihood Parameter Estimates } \\
\hline Crash Type & Injury Level & Parameter & Estimates & Pr $>$ ChiSq & AIC \\
\hline \multirow{3}{*}{ All } & \multirow{3}{*}{ All } & Intercept & -11.245 & $<0.0001$ & \\
\cline { 3 - 5 } & & Log AADT & 1.6272 & $<0.0001$ & \multirow{2}{*}{186.648} \\
\cline { 3 - 6 } & \# of tollbooths & 0.169 & 0.0225 & \\
\cline { 3 - 6 } & Dispersion & 0.143 & & \\
\hline
\end{tabular}

This finding could be attributed to the fact that the AADT is considered as the exposure factor; more traffic at the TMTP would lead to higher chances of crash occurrence. This is expected, since higher AADT results in higher exposure of vehicles to weaving manoeuvres to avoid delay at some lanes which in turn would result in higher crash frequencies. Also, the number of tollbooths was found to be significant, as the number of tollbooths increase the crashes are more likely to be increased, and that may be because of the increase of multiple lane changes.

\subsection{Part II : Effect of the number of the ETC and cash lanes on the safety at TMTP}

Data from 42 Traditional Mainline Toll Plazas (TMTP) also was used in this approach. Crash data from a four-year period $(2011,2012,2013$ and 2014) was investigated. It should be noted that the number of ETC lanes and coin lanes were not significant, therefore it was excluded from the final model. Figure 2 shows Tollbooths Types of Traditional Mainline Toll Plazas. This design combines express lanes and traditional cash lanes.

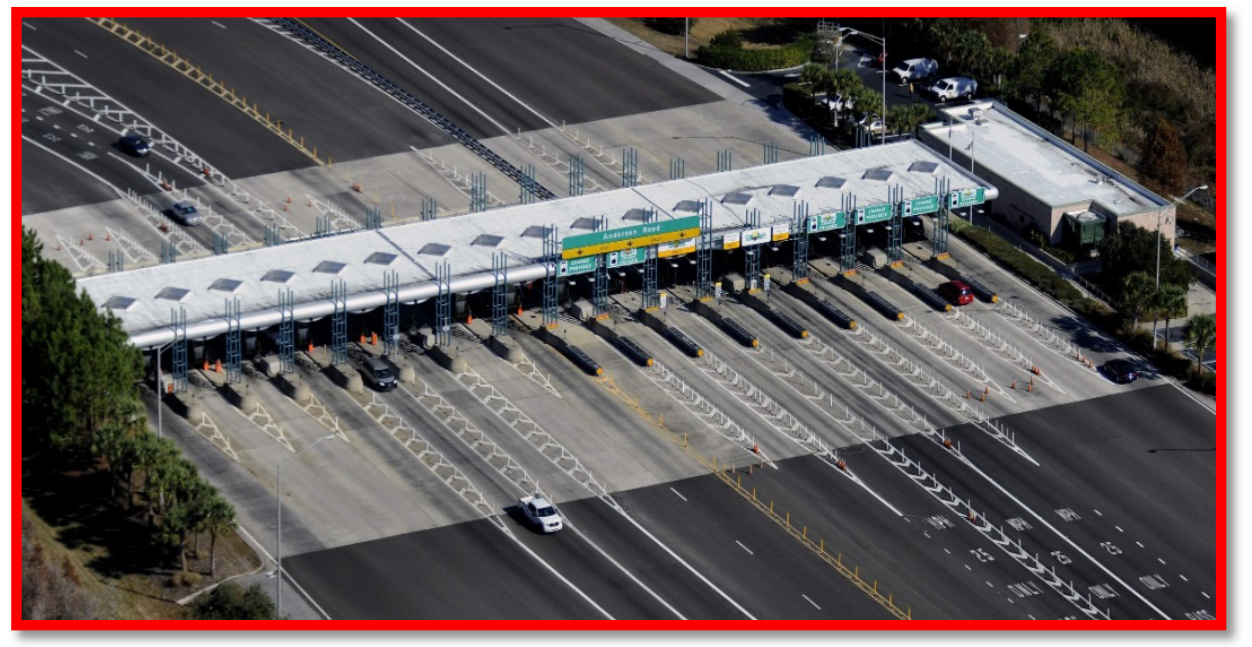

Fig. 2. Tollbooths Types of Traditional Mainline Toll Plazas. (Source: (FTE, 2015))

A series of NB models also were fitted to establish the relationships between traffic, roadway characteristics and crash frequency at the vicinity of TMTPs. The results indicated that the crash frequency was not significantly associated with number of ETC and coin lanes, number of entry and exit ramps, and distance to entry and exit ramps. Table 2 shows the parameter estimates of the final model. 
Table 2. Estimates of coefficients for Effect of the number of tollbooths on TMTP safety.

\begin{tabular}{|c|c|c|c|c|c|}
\hline \multicolumn{5}{|c|}{ Negative Binomial } \\
\hline \multirow{2}{*}{ Crash Type } & Injury Level & Parameter & Estimates & Pr $>$ ChiSq & AIC \\
\hline \multirow{3}{*}{ All } & \multirow{3}{*}{ All } & Intercept & -18.356 & $<0.0001$ & \\
\cline { 3 - 5 } & & Log AADT & 1.846 & $<0.0001$ & \multirow{2}{*}{168.214} \\
\cline { 3 - 5 } & \# of cash lanes & 0.113 & 0.0322 & \\
\cline { 3 - 5 } & Dispersion & 0.126 & & \\
\hline
\end{tabular}

Only log Annual Average Daily Traffic (AADT) and the number of cash lanes came out to be significant with the expected signs. The coefficient of both variables have a positive sign, which indicates that as they increase, the frequency of TMTP-related crashes increases.

This finding could be attributed to the fact that the AADT is considered as the exposure factor; more traffic at the TMTP would lead to higher chances of crash occurrence. This is expected, since higher AADT results in higher exposure of vehicles to weaving maneuvers (change lanes) between cash lanes and ETC lanes, which in turn would result in higher crash frequencies. Also, the number of cash lanes found to be significant.

Therefore, as the number of cash lanes increase, the crashes are more likely to be increased, and that may be because of the increase of the lane changes between the different types of lanes. The number of ETC lanes and coin lanes were not significant and that maybe because most of the locations in this study have similar number of the ETC and coin lanes. Therefore, it is strongly recommended to be reevaluated with different data to reach a constant conclusion about the effect of the number of the coin lanes at the traditional mainline toll plaza.

\section{Conclusions}

Expressways (toll roads) and freeways are considered an important part of any successful transportation system. These facilities carry the majority of daily trips on the transportation network. Although toll roads offer a high level of service, traditional plazas still experience many crashes, many of which are severe. Therefore, this study examines for the first time the traffic safety impact of the number and types of tollbooths on the traditional mainline toll plaza. And that by helping understand the relationship between the crash frequency and several important crash-related factors and circumstances such as traffic volume, total number of tollbooth and the number of cash lanes.

Crash data from four-year period was investigated, and 42 traditional mainline toll plazas were evaluated. The current data has indicated that the number of tollbooths and the number of the cash lanes were found to be significant in the final models. Therefore, as the number of toll booths increase the crashes are more likely to be increased, and that may be because of the increase of the potential of making multiple lane changes. Moreover, this study showed that as the number cash lanes increase, the crashes also are more likely to be increased.

The number of ETC lanes and coin lanes were not significant and that maybe because most of the locations in this study have similar number of the ETC and coin lanes. Therefore, it is strongly recommended to be reevaluated with different data to reach a 
constant conclusion about the effect of the number of the ETC and coin lanes at the traditional mainline toll plaza.

The results indicated significant relationships between the crash frequency and the number of tollbooths, number of the cash lanes and the annual average daily traffic. This means all of these variables significantly affect the frequency of the traditional toll plazasrelated crashes. For those agencies that need to adopt this design of the toll collection system, improving traffic safety at these facilities should take a priority.

Overall, choosing locations for the toll plazas that have safe distances from the interchanges, installing flashing lights at night time, and finding ways to improve signage and road marking are potential means of reducing lane changes before tollbooths. These finding are very important as a first step to evaluate these facilities and researchers may build on these results to reach a clear conclusion.

\section{References}

1. Abdel-Aty, M. and Radwan, E. "Modeling Traffic Accident Occurrence and Involvement." Accident Analysis and Prevention No. 32, 633-642. (2000)

2. Abuzwidah, M. "Evaluation and Modeling of the Safety of Open Road Tolling System" M.S. Thesis. Orlando, University of Central Florida. (2011)

3. Abuzwidah, M., Abdel-Aty, M., and Ahmed, M. "Safety Evaluation of Hybrid Mainline Toll Plazas". Journal of the Transportation Research Board, in press. (2014)

4. Agresti, A. Categorical data analysis. New York: Wiley-Interscience. (2002)

5. Brown, L., D.R., McDonald, and E.J. Myers. Developing Traffic Control Strategies at Toll Plazas. ITE Journal, November, pp. 22-26. (2006)

6. Central Florida Expressway Authority (CFX). https://www.oocea.com . Last access Jan 2017.

7. Chang, L. Analysis of freeway accident frequencies: Negative binomial regression versus artificial neural network. Safety Science, (8), 541. (2005)

8. Chen, C. Statistical analysis of the effect of demographic and roadway factors on traffic crash involve ment. (1997)

9. Federal Highway Administration (FHWA), Manual on Uniform Traffic Control Devices (MUTCD) Chapter 2F. http://mutcd.fhwa.dot.gov/knowledge/faqs/faq part2.htm Last access Jan 2017.

10. Florida Department of Transportation (FDOT). http://www.dot.state.fl.us/ . Last access Jan 2017.

11. Florida Turnpike Enterprise TOLL-BY-PLATE. https://www.tollbyplate.com/index . Last access Jan 2017. (FTE, 2015)

12.Kim, K., Nitz, L., Richardson, J. and Li, L. Personal and behavioral predictors of automobile crash and injury severity. Accident Analysis and Prevention 27, 4, 469-481. (1995)

13. McDonald, D. and R. Stammer. Contribution to the Development of Guidelines for Toll Plaza Design. Journal of Transportation Engineering, Vol. 127, No. 3, pp. 215-222.

14. Miami-Dade Expressway. http://www.mdxort.com/. Last access Jan 2017.( 2001)

15. Mohamed, A., Abdel-Aty, M. and Klodzinski, J. Safety Considerations in Designing Electronic Toll plazas: Case Study. ITE Journal. (2000) 
16. National Transportation Safety Board (NTSB). http://www.ntsb.gov/. Last access Jan 2017.

17. Schaufler, A.E. NCHRP Synthesis of Highway Practice 240: Toll Plaza Design. Transportation Research Board of the National Academies, Washington, D.C., (1997)

18. Sze, NN, SC Wong, and WF Chan. n.d. "Traffic crashes at toll plazas in Hong Kong." Proceedings Of The Institution Of Civil Engineers-Transport 161, no. 2: 71-76. (2008)

19. Wong, S., Sze, N., Hung, W., Becky, P., \& Lo, H. (n.d). The effects of a traffic guidance scheme for auto-toll lanes on traffic safety at toll plazas. Safety Science, 44(9), 753-770.

20. Yang, H., Ozbay, K., Bartin, B., and Ozturk, O. "Assessing the Safety Effects of Removing Highway Mainline Barrier Toll Plazas." J. Transp. Eng., 10.1061/ (ASCE) TE.1943-5436.0000681, 04014038. (2014) 